\title{
Probabilities will help us plan for climate change
}

\section{Without estimates, engineers and planners will have to delay decisions or take a gamble.}

Sir - In his Commentary "What is

'dangerous' climate change?", Stephen

Schneider ${ }^{1}$ argued that — in the absence of unambiguous expert advice - decisionmakers will produce their own probability estimates about future climate change within the large range of projections provided by the Intergovernmental Panel on Climate Change (IPCC) in its Third Assessment Report, and that this is worse than using informed estimates provided by relevant experts. On the other hand, Grübler and Nakicenovic ${ }^{2}$ in a subsequent Correspondence, "Identifying dangers in an uncertain climate", argue that providing well-founded probability estimates is difficult or impossible because, although probabilities in the natural sciences are based on repeated experiments and frequencies of measured outcomes, this is not the case in the socio-economic sciences.

However, this frequentist basis for probabilities in predictions of an unknown future is not possible in the Earth sciences either, since there will only be one real outcome, which cannot be measured now. Probability estimates of future conditions on Earth based on modelling are not frequentist, but essentially bayesian ${ }^{3}$, in that they are based on prior knowledge or assumptions embodied in the various models and inputs.

Various authors have shown that such estimates for global warming are possible ${ }^{1,4,5}$ by deriving single-peaked probability distributions. On the other hand, Gritsevskyi and Nakicenovic ${ }^{6}$ obtain a bimodal probability distribution of carbon dioxide emission amounts for the year 2100, which they attribute to a bifurcation in technological development pathways. If this bimodal distribution were combined with other factors to derive a probability distribution for global warming, it would almost certainly be smoother, but could still differ significantly from the other distributions.

Thus, although probability estimates are needed, methods for deriving probabilities require further development ${ }^{7}$. Some authors have suggested that in the meantime we should rely on increasing robustness ${ }^{8}$ or resilience ${ }^{9}$ in developing mitigation and adaptation responses. But without well-founded probability estimates, these strategies still tacitly assume some estimates of likelihood to limit the magnitude of their responses in relation to costs.

In fact, a risk-management approach requires not an assessment of the probability of a particular amount of greenhouse-gas emission or global warming at some future time, but rather an estimate of the likelihood of exceeding an identified critical impact threshold ${ }^{10}$. This integrates the probabilities from the least climate change up to the critical level, and is much more robust with respect to the underlying assumptions.

In the IPCC Third Assessment Report discussed in ref. 1 , the uncertainties in projections of global surface warming by 2100 derive almost equally from uncertain emissions and uncertain climate science. Thus if critical thresholds for impacts lie in the top half of the predicted range of global warmings, these are much more likely to be avoided if decision-makers attempt to follow socio-economic development pathways that will reduce emissions. The virtue of the range of socio-economic development pathways explored by IPCC in ref. 11 is that it suggests that there are various plausible socio-economic futures that will achieve this goal. Such development pathways may still lead to appreciable warming by 2100 and beyond, which can be avoided only by stringent climate policies.

Without probability estimates, engineers and planners will be left needing to foster resilience and adaptive capacity, hedge their bets, delay their decisions, or else gamble on whether humanity will go down high or low emissions development pathways as they adapt design standards and zoning to climate change.

It is far more sensible to establish cumulative probability distributions to allow optimal, focused adaptation plans. A. Barrie Pittock, Roger N. Jones, Chris D. Mitchell

Climate Impact Group, CSIRO Atmospheric Research, PMB 1, Aspendale 3195, Australia

1. Schneider, S. H. Nature 411, 17-19 (2001).

2. Grübler, A. \& Nakicenovic, N. Nature 412, 15 (2001).

3. Malakoff, D. Science 286, 1460-1464 (1999).

4. Webster, M. D. et al. Uncertainty Analysis of Global Climate Change Projections, Report No. 73, MIT Joint Program on the Science and Policy of Global Change (Cambridge, MA, 2001).

5. Wigley, T. M. L. \& Raper, S. C. B. Science 293, 451-454 (2001).

6. Gritsevskyi, A. \& Nakicenovic, N. Energy Policy 28, 907-921 (2000).

7. New, M. \& Hulme, M. Integrated Assessments 1, 203-213 (2000).

8. Lempert, R. J. \& Schlesinger, M. E. Climatic Change 45, 387-401 (2000)

9. Barnett, J. World Development 29, 977-993 (2001). 10.Jones, R. N., Natural Hazards 23, 197-230 (2001).

11.Nakicenovic N. \& Swart, R. Special Report of the Intergovernmental Panel on Climate Change on Emissions Scenarios (Cambridge Univ. Press, Cambridge, 2000).

\section{Vital parameters need to be in print}

Sir — In an effort to condense Letters to Nature in the printed version of the journal, there is a risk that some of the critical information necessary for an independent judgement of the quality of biological structural information may be omitted, appearing only in the Supplementary Information available in the online version.

These indicators are: the resolution of the structure determination; the 'free $\mathrm{R}$ factor' (an unbiased metric of agreement between the experimental X-ray diffraction data and the derived molecular model); and the Ramachandran analysis (the only independent measure of a model's stereochemical reasonableness).

In some cases, this critical information — which takes little space - is excluded, whereas non-essential information, such as the location of the synchrotron beamlines where the diffraction data were collected and the names of standard programs used to determine the structure, is included in the printed version. It is often inconvenient to have to access the Internet while reading a paper in print, in order to obtain these essential quality indicators.
The crystallographic community has had a welcome change of heart on agreement about validation criteria for structural models - critical use of the indicators I have mentioned above — and on data availability via deposition in publicly available databases. Given that Nature has fully supported this shift, should the journal not also enforce minimal, accessible reporting of a structure's quality indicators in the printed versions of papers, rather than allowing authors to deposit all this information in the online-only format of Supplementary Information?

\section{David Borhani}

Abbott Bioresearch Center, 100 Research Drive, Worcester, Massachusetts 01605, USA

Nature's policy is to include in the printed versions of its papers sufficient technical information to allow an interested reader to appreciate the experiments that have been performed, along with the most critical experimental data. We would therefore normally expect essential structural parameters to be included in the published version of papers rather than as part of the Supplementary Information only. However, this is always assessed by Nature on a case-bycase basis - Editor, Nature. 